\title{
An Optimal Power Flow Control Method for Grid-Connected Inverters
}

\author{
Navid Yektay, Ali Darudi, Mohammad Hossein Javidi \\ Dept. Electrical Engineering \\ Ferdowsi University of Mashhad \\ Mashhad, Iran
}

\begin{abstract}
Most of the modern renewable energy technologies generate DC electric power, which is incompatible with AC grids. In order to control the power flow from DC bus of such generating units to $\mathrm{AC}$ grids, grid-connected inverters are essential. This paper proposes an optimization-based control method for single-phase grid-connected inverters which could be considered as a mixture of Model Predictive Control (MPC) and Direct Power Control (DPC). The proposed method minimizes switching frequency and, simultaneously, takes into account power quality constraints such as standard output current harmonics and Total Harmonic Distortion (THD). Due to long computational time required for running optimization problem, solutions for a set of outputs are computed off-line and stored in a look-up table. An open-loop control method based on the look-up table is proposed. Furthermore, in order to provide small signal regulation and disturbance compensation, an on-line algorithm is implemented. Simulation results assure that, the method works accurately in an ideal environment and dramatically lower switching frequencies are achieved. In addition, the closed-loop method not only provides continuous control on output power, but also compensates possible disturbances.
\end{abstract}

Keywords- grid-connected inverters; Optimality; Model Predictive Control, Direct Power Control

\section{Nomenclature:}

$\begin{array}{cl}\left(\mathrm{P}_{\mathrm{e}}, \mathrm{Q}_{\mathrm{e}}\right) & \text { Error of output active and reactive power } \\ \left(\mathrm{P}_{\text {out }}, \mathrm{Q}_{\text {out }}\right) & \text { Output active and reactive power } \\ \left(\mathrm{P}_{\text {out.p }}, \mathrm{Q}_{\text {out.p }}\right) & \begin{array}{l}\text { Output active and reactive power of optimal switching } \\ \text { pattern }\end{array} \\ \left(\mathrm{P}_{\text {ref }}, \mathrm{Q}_{\text {ref }}\right) & \text { Reference values for active and reactive power } \\ \left(\mathrm{P}_{\text {rep }}, \mathrm{Q}_{\text {rep }}\right) & \text { Desired output active and reactive power } \\ \theta & \text { Phase angle of grid voltage } \\ \mathrm{a}_{\mathrm{n}}, \mathrm{b}_{\mathrm{n}} & \text { Fourier series coefficients } \\ \mathrm{f}_{\mathrm{sp}} & \text { Average switching pattern frequency } \\ \mathrm{I}_{\mathrm{n} . \mathrm{p}} & \mathrm{n}^{\text {th }} \text { output current harmonic of optimal switching } \\ & \text { pattern } \\ \mathrm{I}_{\mathrm{n}}^{*} & \begin{array}{l}\text { Maximum standard value for } \mathrm{n}^{\text {th }} \text { output current } \\ \text { harmonic }\end{array} \\ & \text { Value of filt indutor }\end{array}$

L Value of filter inductor

$\begin{array}{cl}\mathrm{LF} & \begin{array}{l}\text { Nominal grid frequency }(50 \mathrm{or} 60 \mathrm{~Hz}) \\ \mathrm{n}\end{array} \\ \mathrm{N} & \begin{array}{l}\text { Harmonic indicator } \\ \text { standards }\end{array} \\ \mathrm{V}_{\mathrm{dc}} & \begin{array}{l}\text { Voltage of DC link } \\ \mathrm{V}_{\text {grid }}\end{array} \\ \mathrm{V}_{\mathrm{n},} \varphi_{\mathrm{n}} & \text { Grid voltage } \\ \mathrm{V}_{\text {out }}(\theta) & \text { Amplitude and phase of }{ }^{\text {th }} \text { voltage harmonics } \\ \mathrm{THD}_{\mathrm{p}} & \text { Total harmonic distortion of optimal switching pattern } \\ \mathrm{T}^{*}{ }_{\text {off }} & \text { Minimum duration that switches could be off } \\ \mathrm{T}^{*}{ }_{\text {on }} & \text { Minimum duration that switches could be on } \\ \mathrm{T}_{\text {off }} & \text { Time duration that switches are off } \\ \mathrm{T}_{\text {on }} & \text { Time duration that switches are on }\end{array}$

I. INTRODUCTION

\section{A. Motivation}

Over the last few decades, a great deal of research have been carried out on renewable energy resources due to environmental concerns and fossil fuel shortage. Therefore, photovoltaic systems, modern wind turbines and other types of renewable technologies are being utilized in the grid and their share in power generation is growing exponentially. Unfortunately, these technologies mainly generate DC electric power, which is incompatible with $\mathrm{AC}$ grids. In order to control the power flow from DC bus of these generating units to AC grids, grid-connected inverters are needed $[1,2]$. Single-phase inverters, in opposition to three-phase types, are being popular due to their compatibility with low power renewable energy resources.

Grid-connected inverters are desired to have the following characteristics: high efficiency, output power regulation, high power quality, low Total Harmonic Distortion (THD), high reliability, low cost, high robustness to perturbations, fast dynamic response and simple circuitry $[3,4]$. In order to achieve most of these characteristics, this paper presents a new power flow control strategy for single-phase inverters which is based on optimization theory. 


\section{B. Literature Review}

Up to now, several techniques have been proposed to control the power flow of single-phase grid-connected inverters. They might be categorized into conventional and modern methods. Conventional techniques include Current Hysteresis Control (CHC), Voltage Oriented Control (VOC) and Proportional-Resonant (PR) control, while modern techniques contain methods like Direct Power Control (DPC), Deadbeat Control and Model Predictive Control (MPC).

VOC is the most popular technique due to fixed switching frequency and low output current THD at relatively small switching frequencies; however, it has a complex structure; and in single-phase applications, generation of a fictitious phase is needed [1]. CHC technique presents convenient dynamic response and simple implementation; nevertheless, it requires high switching frequency and filter inductance to have appropriate output characteristics. None of the aforementioned techniques directly consider power quality constraints such as output current harmonics or THD. Instead, in order to meet power quality standard constraints, the conventional methods simply increase switching frequency.

This paper proposes a control method which is roughly a mixture of MPC and DPC; therefore, we briefly introduce them in following paragraphs.

MPC is one of the most recent control techniques in power electronics, which has gained popularity due to improvements in microprocessors' performance. Generally, MPC is referred to any control algorithm which utilizes model of the system to predict its behaviors. Then, based on predicted values, the most suitable control action is chosen such that a certain performance index is optimized [5]. The performance index may cover different control objectives such as achieving low current or power error, fixed switching frequency or low switching losses. Direct Power Control (DPC) was first introduced by Ohnishi in 1991 [6]. It aims to determine states of the switches such that error of active and reactive power is minimized in the next sampling period. According to measured power error and the phase of the grid voltage, DPC refers to a predefined table, called switching look-up table, to determine the appropriate states for the switches. One of the most serious challenges of DPC method is how to define an appropriate switching look-up table.

\section{The Proposed Method and Contributions}

This paper redefines power flow control of single-phase grid-connected inverters as an optimization problem (like MPC). Unlike conventional MPCs, we set infinite time as the optimization time horizon to obtain better performance. However, due to computational burden, we calculate optimal solutions off-line and store them in a look-up table (like DPC). Output active and reactive power regulation is achieved by implementing a mixture of off-line and on-line algorithms.

The contribution of the paper is mainly two-fold:

1- Power quality constraints such as maximum standard THD of the output current is directly considered in the MPC.
2- Optimization problem is defined such that its time horizon could be considered as infinite, whilst conventional MPCs only takes one or two sampling periods as the time horizon. Considering a longer time horizon generally provides solutions with better performance.

The main objective of the proposed method is to minimize switching frequency, which leads to higher energy efficiency, lower electromagnetic interference (EMI), cheaper switches and simpler cooling systems. Moreover, the method might be suitable for applications that only low frequency switches are available like high-power converters

\section{Paper Organization}

The rest of the paper is organized as follows. Section II presents a new open-loop and also a complementary closedloop method which aids the open-loop algorithm to be stable and accurate under parameter variations and system disturbances. Section III includes formulation of the problem. Section IV presents simulation results of the method. Finally, the paper is summarized and concluded in section $\mathrm{V}$.

\section{PROPOSED CONTROL METHOD}

The aim of this paper is to propose a control method for single-phase grid-connected inverters. The method minimizes switching frequency (objective function) and simultaneously, takes into account power quality standards and output power regulation (constraints). Considering control of gird-connected inverters as an optimization problem, states of the switches (on/off) corresponding to phase angle of grid voltage is selected as the decision variable.

Based on the reality that the grid voltage could be assumed periodic, switching patterns are calculated for the full period of grid voltage and applied periodically. In fact, for a given active and reactive power, optimization solution (the switching pattern) would be states of the switches corresponding to phase angle of the grid voltage. We call this approach Full Period Switching Pattern Optimization (FPSPO). The proposed method might be classified as an MPC. This problem is defined and formulated in section III.

Conventional MPC approaches [7, 8] apply optimization just for a limited finite time horizon ( 1 or 2 sampling periods). We applied a longer time horizon which leads to better performance. Therefore, when frequency minimization is the objective function, lower switching frequency might be achieved.

Although FPSPO potentially leads to better performance, it is not practical to be performed in on-line applications; because the optimization problem is complex and time consuming. To avoid unbearable on-line computational burden, FPSPO is carried out off-line for each desired output power and the solutions are stored in a look-up table. Therefore, on-line procedure is just identifying phase angle of the grid voltage and applying gates' signals from the appropriate part in the look-up table. 


\section{A. Implementation of Open-loop Control Method}

This section describes details of the proposed open-loop control method. Inverters should be able to regulate output active and reactive power $\left(\mathrm{P}_{\text {out }}, \mathrm{Q}_{\text {out }}\right)$. As mentioned earlier, optimal solutions for a particular $\left(\mathrm{P}_{\text {out }}, \mathrm{Q}_{\text {out }}\right)$ can be obtained by solving corresponding FPSPO problem. Inverters should be able to control power output in a desired P-Q operating region, not for a particular $\left(\mathrm{P}_{\text {out }}, \mathrm{Q}_{\text {out }}\right)$. Since it is not practical to carry out FPSPO for any ordered pair of $\left(\mathrm{P}_{\text {out }}, \mathrm{Q}_{\text {out }}\right)$ in the desired $\mathrm{P}$ $\mathrm{Q}$ operating range, we divide the range into several subregions and only one ordered pair in each sub-region is chosen as a representative point to run FPSPO for. For example, as shown in Fig. 1, assume that the control region is $[0,1]$ for $\mathrm{P}_{\text {out }}$ and $[-0.5,0.5]$ for $Q_{o u t}$ in per units. The operating range is divided into 9 sub-regions and consequently, 9 representatives (ordered pairs shown by dots) are selected. Accordingly, 9 FPSPO solutions are stored in the look-up table.

Control diagram of the open-loop method is shown in Fig. 2. According to reference of active and reactive power $\left(\mathrm{P}_{\text {ref }}, \mathrm{Q}_{\mathrm{ref}}\right)$, the $P-Q$ region selector block picks out the closest switching pattern of the look-up table. The selected pattern is the switches' states corresponding to phase angle of grid voltage $(\theta)$; therefore, first we need to identify $\theta$ using the phase locked loop (PLL) block. Then the gate signal generator block is responsible for determining the appropriate part of selected switching pattern using $\theta$.

In order to overcome the shortcoming of the method that only discrete control of active and reactive power is available, a modifying algorithm is introduced in section II, which is responsible for small signal regulation and disturbance compensation.

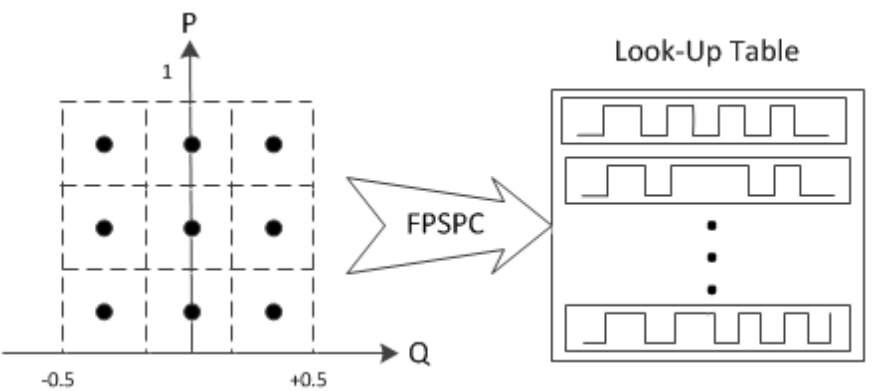

Fig. 1: FPSPO is carried out for representative points of the operating range

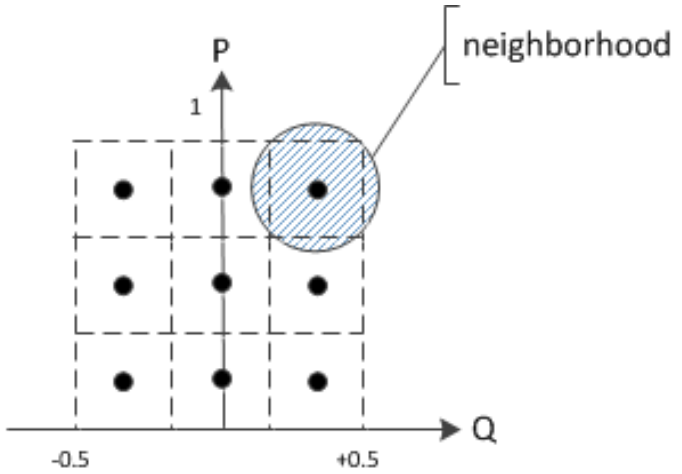

Fig. 3: A neighborhood around one of the representatives

\section{B. Implementation of Close-loop Control Method}

In this section, we propose a complementary closed-loop method which aids the open-loop algorithm to be stable and accurate under parameter variations and system disturbances. As mentioned earlier, for any $\left(\mathrm{P}_{\text {ref }}, \mathrm{Q}_{\mathrm{ref}}\right)$ that is not precisely equal to any of the representative points, output steady-state error occurs. Thus, in error-sensitive applications, it is necessary to increase the number of representative points. Unfortunately, this approach is not practical because it not only requires excessive storage space for the look-up table, but also takes up too much time for running FPSPOs which is not acceptable even for off-line calculations.

In order to keep the number of representative points low and also maintain inverter's performance high, we suggest an on-line-implementable algorithm that utilizes stored solutions (switching patterns for representative points) to extrapolate other points in P-Q space. The algorithm manipulates switching patterns of representative points in a way that a neighborhood of each representative point becomes accessible (Fig. 3). As a result, ( $\mathrm{P}_{\text {out, }} \mathrm{Q}_{\text {out }}$ ) may be controlled continuously. The modified control diagram (Fig. 4) is the same as open-loop control (Fig. 2) except for the feedback loop and the $P-Q$ fine-tuner block. Feedback loop measures the remaining error of output $\left(\mathrm{P}_{\mathrm{e}}, \mathrm{Q}_{\mathrm{e}}\right)$. To compensate the error, the $P-Q$ fine-tuner block reforms switching pattern provided by $P-Q$ region selector block. To control active power, the $P$ - $Q$ fine-tuner block slightly shifts the phase angle of the switching pattern; and to modify reactive power, it increases/decreases first harmonic amplitude of the switching pattern. These approaches are inspired by the fact that transferred active and reactive power across an inductance is highly associated with terminals voltage phase angles and

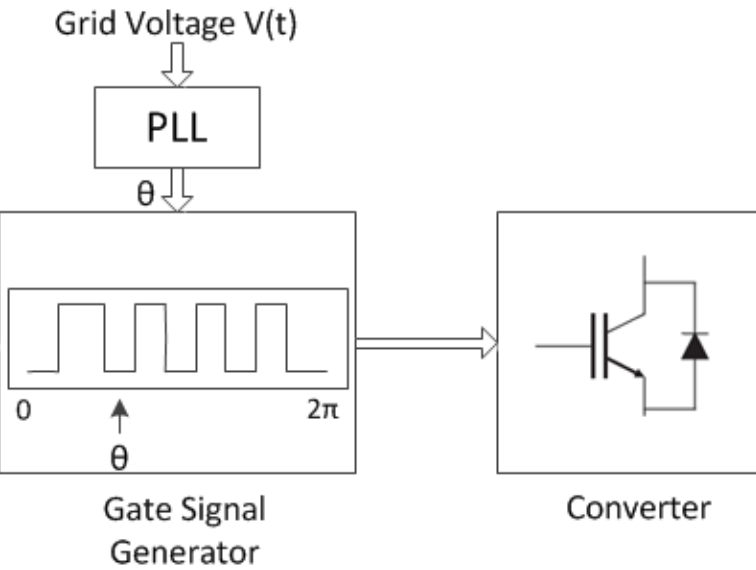

Fig. 2: Control diagram of the open loop method 


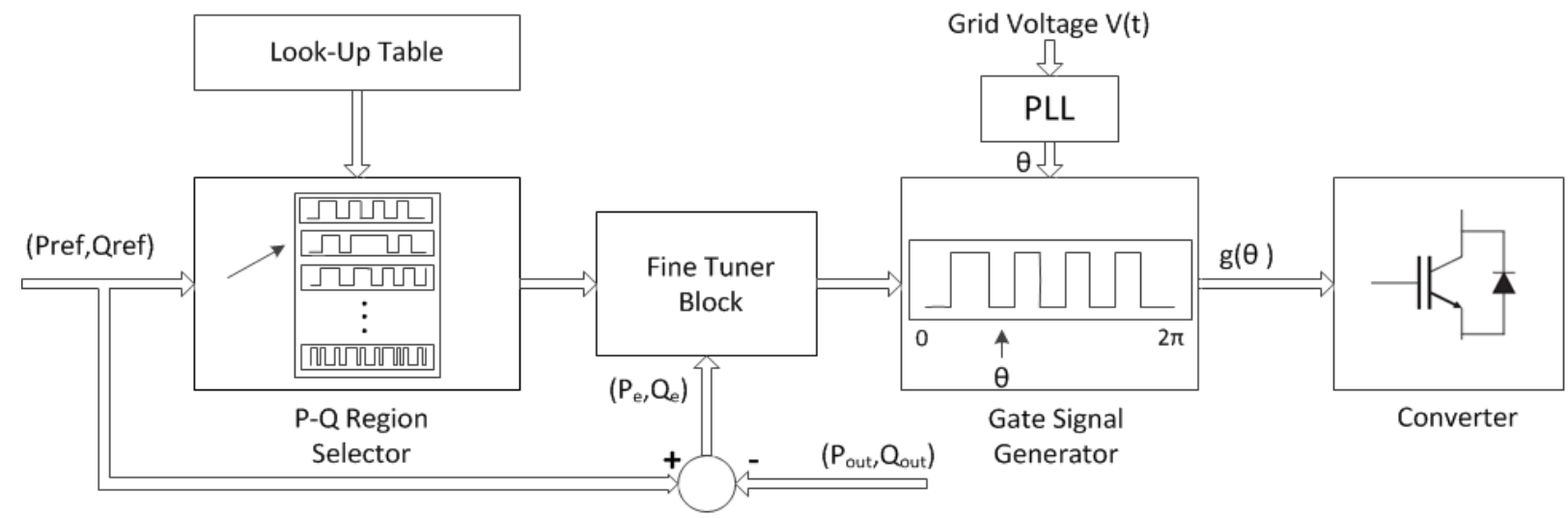

Fig. 4: Control diagram of the closed-loop method

amplitudes, respectively $[9,10]$. Due to space limitations, this block is not explained in details.

Although the fine-tuning algorithm is designed such that the inverter's switching frequency is not affected, output power quality might be deteriorated. Thus, to avoid violation of power quality constraint, it is necessary to define power quality constraints conservatively in FPSPO.

\section{FPSPO FORMULATION}

In this section, we present formulation of FPSPO for a particular desired active and reactive output power. Similar to other optimization problems, FPSPO consists of three major parts: objective function, decision variables and constraints. Detailed formulation of FPSPO mainly depends on topology of the implemented power circuit, structure of the output filter and also grid model.

This paper focuses on controlling a grid-connected singlephase inverter with two-level full-bridge topology. Output filter of the converters is a simple inductor. As shown in Fig. 5 , the grid is modeled just as an ideal AC voltage source. Based on these assumptions, details of FPSPO are introduced in the following paragraphs:

$f_{s p}=0.5 \times($ changes in switching pattern $) * \operatorname{LF}(1)$

$$
\begin{aligned}
& \text { Min } f_{\text {sp }} \\
& \quad V_{\text {out }}(\theta) \\
& \text { st }: \\
& \forall \theta \in[0,2 \pi) \quad V_{\text {out }}(\theta) \in\left\{-V_{D C},+V_{D C}\right\} \\
& P_{\text {out. }} \approx P_{\text {rep }} \\
& Q_{\text {out.p }} \approx Q_{\text {rep }} \\
& I_{n . p} \leq I_{n}^{*} \quad \forall n \in\{2,3, \ldots, N\} \\
& T H D_{p} \leq T H D^{*} \\
& T_{\text {on }}, T_{\text {off }} \geq T_{\text {on }}^{*}, T_{\text {off }}^{*}
\end{aligned}
$$

Objective function: minimizing the average switching frequency $\left(\mathrm{f}_{\mathrm{sp}}\right)$ is chosen as the objective function. $\mathrm{f}_{\mathrm{sp}}$ depends on both changes in switching patterns and also the grid frequency or the line frequency (LF). Assuming the LF to be constant at its nominal value $(50 \mathrm{~Hz}),(1)$ is derived:

Decision variable: The actual control variable of the converter is states (on/off) of the four switches corresponding to phase angle of the grid voltage. Each specific switching pattern results in a certain output voltage $\left(\mathrm{V}_{\text {out }}(\theta)\right)$ and vice versa. Therefore, for the sake of simpler definition of the optimization problem, instead of the states of the switches, output voltage of the converter corresponding to the phase angle of the grid voltage $\left(\mathrm{V}_{\text {out }}(\theta)\right)$ is chosen as the decision variable.

Constraints: There are several constraints for FPSPO problem. Equation (2) indicates that $\mathrm{V}_{\text {out }}$, the decision parameter, is assumed to take values from the set $\left\{+\mathrm{V}_{\mathrm{dc}},-\mathrm{V}_{\mathrm{dc}}\right\}$. Equations (3) and (4) express that output active and reactive power of the solution, respectively denoted by $\mathrm{P}_{\text {out.p }}$ and $\mathrm{Q}_{\text {out.p }}$, must be approximately equal to the desired values $\left(\mathrm{P}_{\text {rep }}\right.$ and $\left.\mathrm{Q}_{\text {rep }}\right)$ for which the FPSPO is ran. This approximation simplifies solving the problem. In practice, this approximation will not cause output error; because the closedloop algorithm will eventually compensate it.

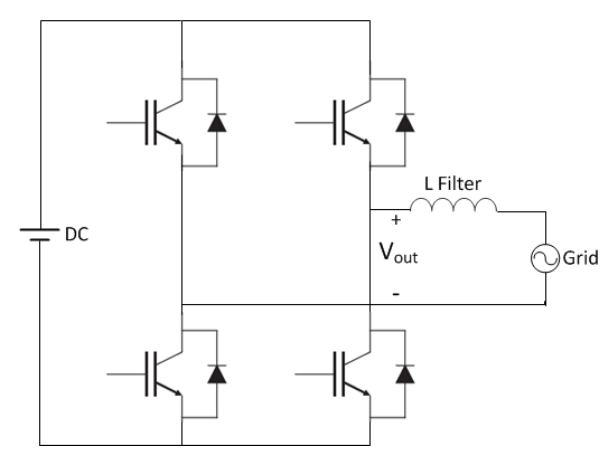

Fig. 5: Power circuit topology of the grid-connected inverter

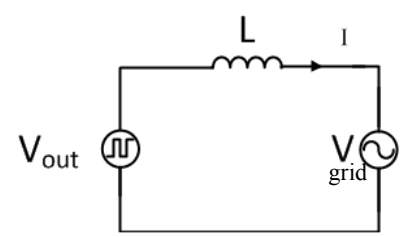

Fig. 6: Equivalent circuit of the power stage of the grid-connected inverter 

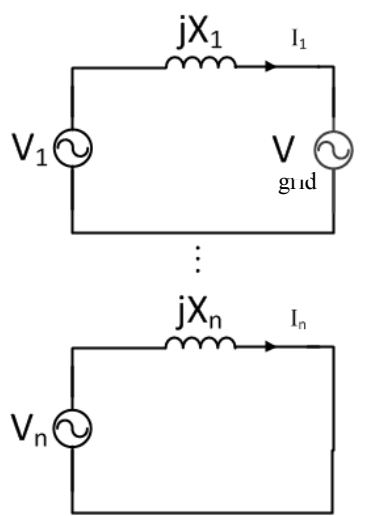

Fig. 7: Equivalent circuit of the power stage of the grid-connected inverter decomposed in frequency-domain

Output current harmonics $\left(\mathrm{I}_{\mathrm{n} . \mathrm{p}}\right)$ and current THD $\left(\mathrm{THD}_{\mathrm{p}}\right)$ should be limited to certain values $\left(\mathrm{I}_{\mathrm{n}}^{*}\right)$ determined by Power quality standards ((5) and (6)). These standards place limitations on only bounded number of harmonics, as denoted by $\mathrm{N}$ in (5). In addition, (5) might be used to suppress or eliminate specific harmonics from the output current as in Selective Harmonic Elimination (SHE) methods. In such cases $\mathrm{I}_{\mathrm{n}}{ }^{*}$ should be set to zero. Finally, (7) considers minimum off/on time of the switches. Several other constraints may be included in FPSPO, if necessary.

In order to solve FPSPO, it is crucial to calculate $\mathrm{P}_{\text {out }}, \mathrm{Q}_{\text {out }}$ and current harmonics caused by applied switching patterns. In fact, we face a circuitry problem (Fig.6) with a square-wave voltage source, $\mathrm{V}_{\text {out }}(\theta)$.

It is not time-efficient to solve the problem in time domain. A practical approach is to use frequency-domain analysis alongside with the superposition principle. Converting the circuit (Fig. 6) into frequency domain decomposes it into infinite number of circuits. As mentioned earlier, standards concern about only bounded number of harmonics $(\mathrm{N})$; therefore we only need to calculate current harmonics up to $\mathrm{N}^{\text {th }}$ frequency. Consequently, only the first $\mathrm{N}$ frequency domain circuits are considered in calculations. As shown in Fig. 7, since the grid is assumed to be a pure sine-wave voltage source, the grid is short circuited in all frequency domain circuits but the main frequency.

Utilizing Fourier series, $\mathrm{n}^{\text {th }}$ voltage harmonic amplitude and phase of the square-wave is given by (8), (9), (10) and (11).

$$
\begin{aligned}
& \mathrm{a}_{\mathrm{n}}=\frac{1}{\pi} \int_{0}^{2 \pi} v_{\text {out }}(t) \sin (t) \cos \left(n \omega_{0} t\right) d t \\
& \mathrm{~b}_{\mathrm{n}}=\frac{1}{\pi} \int_{0}^{2 \pi} v_{\text {out }}(t) \sin (t) \sin \left(n \omega_{0} t\right) d t \\
& V_{n}=\sqrt{a_{n}^{2}+b_{n}^{2}} \\
& \varphi_{n}=\tan ^{-1}\left(\frac{b_{n}}{a_{n}}\right)
\end{aligned}
$$

Equations (12), (13) and (14) utilize voltage amplitudes to determine harmonic components of the output current.

$$
\begin{aligned}
& I_{1}=\frac{V_{1}-V_{\text {grid }}}{j X} \\
& I_{n}=\frac{V_{n}}{j X_{n}} \quad, n \neq 1 \\
& X_{n}=j \omega L=j n \omega_{0} L
\end{aligned}
$$

Finally, active power, reactive power and THD could be computed as (15), (16) and (17).

$$
\begin{aligned}
P_{\text {out }} & =V_{\text {grid }} I_{1} \operatorname{Cos}\left(\varphi_{1}\right) \\
Q_{\text {out }} & =\sum_{n=1}^{N} V_{\text {grid }} I_{n} \operatorname{Sin}\left(\varphi_{n}\right) \\
T H D & =\frac{\sqrt{I_{2}^{2}+I_{3}^{2}+\ldots+I_{n}^{2}}}{I_{1}}
\end{aligned}
$$

We used a dedicated Genetic Algorithm (GA) to solve FPSPO off-line. GA details are not discussed in this paper due to space limitations.

\section{SimUlation RESUlts}

In order to test FPSPO and proposed open-loop and closed-loop methods, a MATLAB model of single-phase gridconnected inverter is built up and a simulation is ran using Simulink. Some main parameters are as follows: grid voltage $70 \mathrm{~V} / 50 \mathrm{~Hz}, \mathrm{~L}=3.7 \mathrm{mH}, \mathrm{V}_{\mathrm{dc}}=200 \mathrm{~V}$. IEEE-1547 is chosen as the reference for power quality constraints for maximum harmonic components and THD.

\section{A. Open-loop Algorithm and FPSPO}

In order to verify the open-loop method, FPSPO is carried out for $\mathrm{P}_{\text {rep }}=1000$ Watt, and $\mathrm{Q}_{\mathrm{rep}}=0 \mathrm{VAR}$ (the same as [1]). The provided solution was applied to the inverter switches. The simulated output power and harmonics precisely comply with FPSPO calculations, which verify FPSPO formulations. Output current and its harmonic components are depicted in Fig. 8 and Fig. 9 respectively.

In TABLE I, a comparison is made between FPSPO and VOC, CHC and PR method with the same model parameters. FPSPO meets power quality standards at a dramatically lower switching frequency.

\section{B. Close-loop Algorithm}

We simulated two scenarios to verify capability of the proposed close-loop algorithm to regulate power and reject disturbances.

First, we changed ( $\left.\mathrm{P}_{\text {ref }}, \mathrm{Q}_{\mathrm{ref}}\right)$ from (1012.5 W, 0 VAR) to (1000 W, 20 VAR). As illustrated in Fig. 10, the close-loop algorithm was able to regulate output power accurately. Then, we applied the following disturbance to the system at $\mathrm{t}=0.04$ : grid voltage $71 \mathrm{~V}, \mathrm{~L}=3.8 \mathrm{mH}, \mathrm{Vdc}=201 \mathrm{~V}$. Because FPSPO 


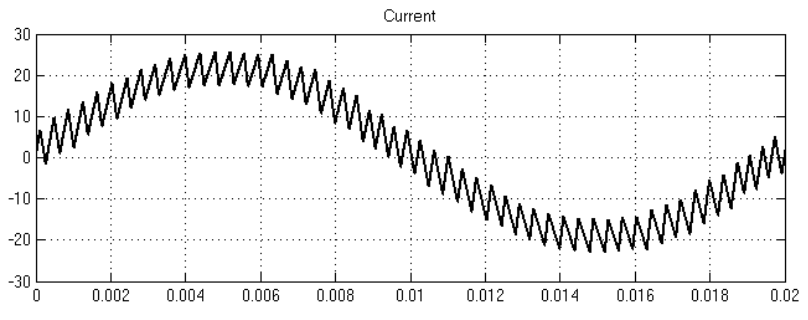

Fig. 8: Steady-state AC current of the inverter $\left(\mathrm{P}_{\text {ref }}=1000\right.$ and $\left.\mathrm{Q}_{\mathrm{ref}}=0\right)$

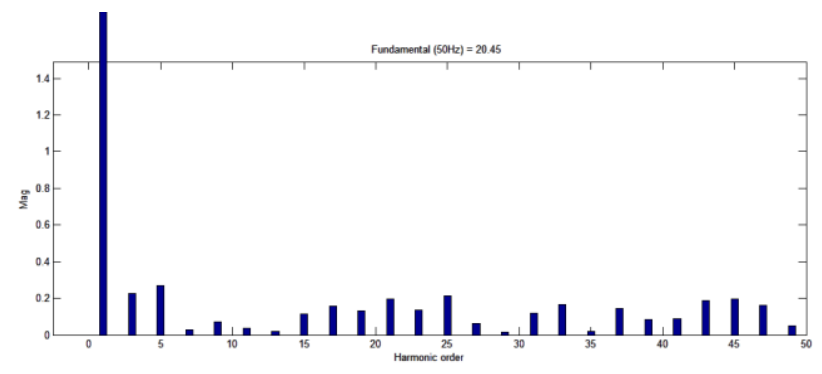

Fig. 9: AC Current harmonic components $\left(\mathrm{P}_{\mathrm{ref}}=1000\right.$ and $\left.\mathrm{Q}_{\mathrm{ref}}=0\right)$

TABLE I: Characteristic comparison FPSPO and other methods

\begin{tabular}{|c|c|c|}
\hline Method & Switching frequency & THD $\%$ \\
\hline CHC1 [1] & $5 \mathrm{KHz}$ & 9.3 \\
\hline CHC2 [1] & $30 \mathrm{KHz}$ & 2.29 \\
\hline VOC [1] & $5 \mathrm{KHz}$ & 2.39 \\
\hline PR [1] & $5 \mathrm{KHz}$ & 2.26 \\
\hline FPSPO & $2.65 \mathrm{KHz}$ & 3.24 \\
\hline
\end{tabular}

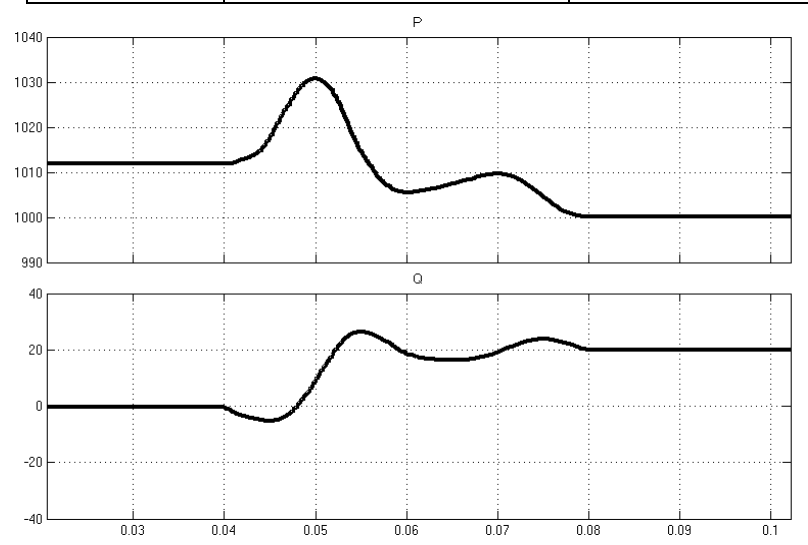

Fig. 10: Transient response operated by the closed-loop algorithm
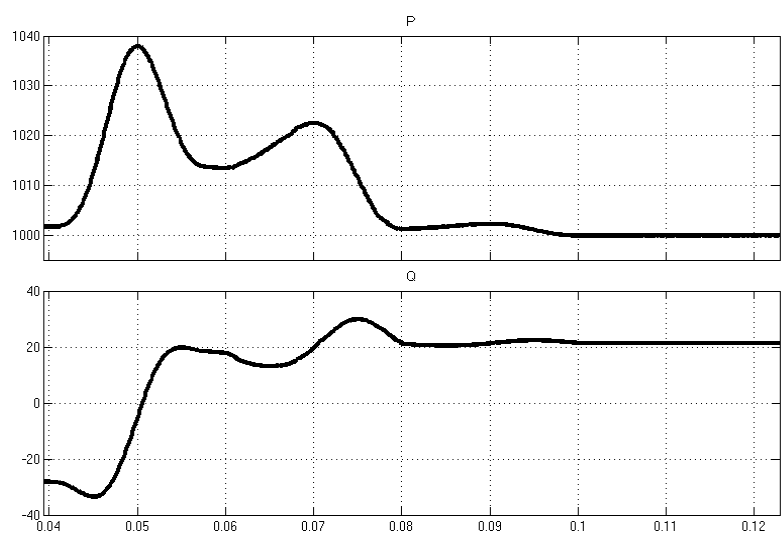

Fig. 11: Disturbance rejection provided by the closed-loop algorithm was carried out for another parameter set, output error in active and reactive power occurs. The fine tuner block gradually modified the former switching pattern. As illustrated in Fig. 11, $\left(\mathrm{P}_{\text {out }}, \mathrm{Q}_{\text {out }}\right)$ reached the reference values after 3 grid cycles.

\section{CONCLUSIONS}

This paper presented an optimization-based control method for single-phase grid-connected inverters. The proposed method minimizes switching frequency and at the same time, takes into account power quality constraints such as standard output current harmonics and THD. Simulation results assure that, the open-loop algorithm works accurately in an ideal environment and dramatically lower switching frequencies are achieved. In addition, the closed-loop method not only provides continuous control on output power, but also compensates possible disturbances. However, at high levels of disturbance, the method may cause violations of power quality constraints. It is notable that Full Period Switching Pattern Optimization method might be used for any other objective functions and even for various quasi-periodical systems such as other grid-connected equipments.

\section{REFERENCES}

[1] Monfared, M.; Golestan, S., "Control strategies for single-phase grid integration of small-scale renewable energy sources: A review", Renewable and Sustainable Energy Reviews, Volume 16, Issue 7, Pages 4982-4993, September 2012.

[2] Shuitao Yang, Qin Lei, “A Robust Control Scheme for Grid-Connected Voltage-Source Inverters", IEEE transaction on industrial electronics, Vol. 58, No. 1, January 2011.

[3] Y. Chen and K. Smedley, "Three-Phase Boost-Type Grid-Connected Inverter," IEEE Transactions on Power Electronics, vol. 23, no. 5, pp. 2301-2309, Sep. 2008.

[4] X. Hao, X. Yang, T. Liu, T. Liu, L. Huang, and W. Chen, "A SlidingMode Controller with Multi-Resonant Sliding Surface for Single-Phase Grid-Connected VSI with an LCL-Filter," IEEE Transactions on Power Electronics, no. c, 2011.

[5] P. Cortés, M. P. Kazmierkowski, R. M. Kennel, D. E. Quevedo and J. Rodríguez, "Predictive control in power electronics and drives," IEEE Trans. Ind Electron., vol. 55, no. 12, pp. 4312-4324, Dec. 2008.

[6] T. Ohnishi, "Three phase PWM converter/inverter by means of instantaneous active and reactive power control," in Proc. Industrial Electronics, Control and Instrumentation, Kobe, 1991, pp. 819-824.

[7] H. M. Kojabadi, B. Yu, I. A. Gadoura, L. Chang, and S. Member, "A Novel DSP-Based Current-Controlled PWM Strategy for Single Phase Grid Connected Inverters," IEEE Transactions on Power Electronics, vol. 21, no. 4, pp. 985-993, 2006.

[8] B. Yu and L. Chang, "Improved Predictive Current Controlled PWM for Single-Phase Grid-Connected Voltage Source Inverters," IEEE 36th Conference on Power Electronics Specialists, 2005., pp. 231-236, 2005.

[9] R. Lasseter, P. Piagi, "Control and Design of Microgrid Components," University of Wisconsin-Madison, pp. 06-03, 2006.

[10] R.H. Lasseter, "Microgrids and distributed generation," Journal of Energy Engineering, 2007. 